Sharif University of Technology
Scientia Iranica
SCIENTIA
I RAN I C A
http://scientiairanica.sharif.edu

\title{
Evaluation of PR steel frame connection with torsional plate and its optimal placement
}

\author{
A. Moghadam, H.E. Estekanchi, and M. Yekrangnia* \\ Department of Civil Engineering, Sharif University of Technology, Azadi Ave., Tehran, P.O. Box 11365-9313, Iran.
}

Received 26 November 2015; received in revised form 2 November 2016; accepted 19 November 2016

\author{
KEYWORDS \\ PR connection; \\ Torsional plate; \\ Plastic rotation; \\ Ultimate moment \\ capacity; \\ Stiffness of the \\ connection; \\ Nonlinear time-history \\ analyses; \\ Finite element \\ method.
}

\begin{abstract}
Characteristics of connections in steel moment-resisting frames are of utmost importance in determining the seismic performance of these structural systems. The results of several previous experimental studies have indicated that Partially Restrained (PR) connections possess excellent properties, which make them a reliable substitution for Fully Restrained (FR) connections. These properties include needing less base shear, being more economic, and, in many cases, being able to absorb more energy. In this study, the behavior of two proposed PR connections with torsional plate is studied through finite element simulations. The results of the numerical studies regarding initial stiffness and maximum strength capacity of the proposed connections are calibrated against the results of solid mechanics formulations. Over 50 parametric studies are performed to determine the importance of various design variables of the proposed PR connections. A relation based on spring model is proposed to estimate the maximum strength capacity of the proposed connection. Seismic performance of the proposed connection is studied in a typical portal frame with various connection characteristics using nonlinear time-history analysis. The results explicitly show that using PR connections can considerably reduce the momentrotation demands in the columns and, as a result, higher performance levels can be achieved according to ASCE41.

(C) 2018 Sharif University of Technology. All rights reserved.
\end{abstract}

\section{Introduction}

Numerous studies indicate that beam-to-column connections have considerable influence on the performance of steel frames. In some cases, connections which do not fall into FR or pin categories are regarded as PR connections. While most steel structures have been designed assuming pin or FR connections, several studies in recent years have aimed to further understand the behavior of PR connections. These studies have shown that PR connections have excellent

*. Corresponding author. Tel.: +982166164270 E-mail addresses: aminmoghadam69@gmail.com (A. Moghadam); stkanchi@sharif.edu (H.E. Estekanchi); yekrangnia@mehr.sharif.edu (M. Yekrangnia)

doi: $10.24200 /$ sci. 2017.4196 properties that make them a preferable alternative to rigid and pin connections. Although much has been achieved in resolving the ambiguities of PR connections, several aspects regarding the behavior of such connections still remain unsolved. In order to fulfill this need, a new PR steel connection is introduced in this study. The performance of this connection is compared with rigid and pin connections in a representative frame that makes use of nonlinear time-history analysis [1]. The schematic representation of the proposed connection is shown in Figure 1. This connection is a welded connection with four plates. The main plate is the torsional plate, connected to the column by two column connection plates and to the beam by a beam connection plate. The main function of the torsional plate is to prevent the surplus moment from the beam to the column, which acts as 


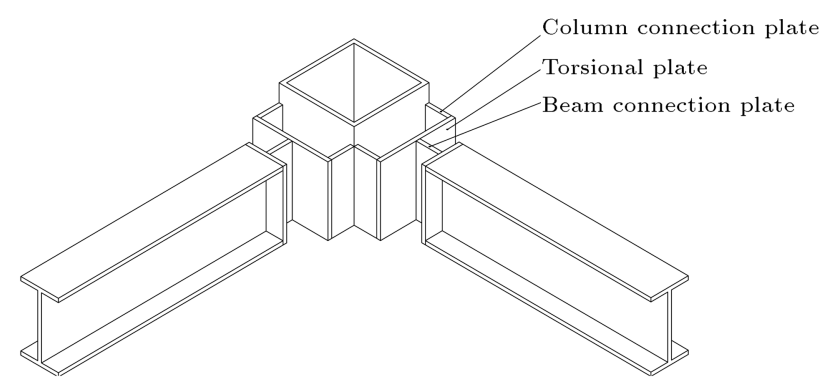

Figure 1. Schematic representation of the proposed Type-1 connection.

a fuse in the connection. Since the torsional plate, especially its thickness, considerably affects the connection behavior, the performance of the structure can be controlled by proper design of torsional plate thickness in the proposed PR connection. In other words, if you set the maximum moment transfer between the beam and the column through the torsional plate, the optimum section size of the frame members can be determined. It is noteworthy that as the flexibility of structures increases, better seismic performance in terms of reducing the number of plastic hinges is achieved [1]. In addition, when you maintain the maximum transferred moment between the beam and the column, the performance level of the structure can increase according to ASCE41-06 [2]. In other words, at an assumed allowable story drift ratio, utilizing the proposed connection can considerably decrease the rotation of hinges.

Different types of beam-to-column connections for box profiles have been introduced in recent years, including fin plate, top and seat angle with or without web angle, T-stub, web cleat, and reverse channel. White and Fang conducted experimental studies on fin plates for beam-to-column connections in box profiles [3]. The results of their studies indicated that this type of connection had strength and ductility capacity and the results of experimental, numerical, and theoretical studies by Jones proved that fin plates performed well under shear and flexural loads [4]. Jones studied the effects of shape and thickness of the column profile, thickness of fin plate, and filling the column with concrete. The observed failure mode included tensile failure in the column plate in the vicinity of the welding and tearing of the fin plate. Wang compared the performance of T-stub connection with fin plate connection [5]. The results indicated that $\mathrm{T}$ stub connection had less flexural stiffness and larger moment-resisting capacity. Dawe and Grondin also performed experimental testing on full-scale beam-tocolumn connections for box profiles [6]. In their study, both compression and tension plates with web cleat angles, and tension plates with sitting angles were investigated. The results, based on eight different failure modes, confirmed the importance of compression and tension plates in the behavior of the studied connection. Elghazouli et al. studied blind-bolted angle connections as beam-to-column connections for box profiles by performing experimental testing [7]. To do this, 17 specimens with different bolt configurations, material properties, columns profiles, and angles dimensions were tested under monotonic and static cyclic loading. It was concluded that the web flange considerably improved the stiffness and strength of the studied connection.

It is noteworthy that fin plate connections cannot be considered a PR connection for reducing moment transferring between the beams and the columns. In response to this need, a new generation of connections (i.e., reverse channel connection) was invented, which has some advantages over the fin plate connections. In an experimental, numerical, and theoretical study conducted by Jones, the behavior of fin plate and reverse channel connections was compared. It was concluded that the latter connection had more shear and flexural capacity than the former one [4]. Ten monotonic and static cyclic tests were performed by Elghazuli and Malaga on beam-to-column connections for box profiles with reverse channel and flange angles [8]. The study determined the important structural responses in terms of stiffness, strength, and energy dissipation capacity. A special type of reverse channel connections was evaluated by $\mathrm{Li}$ where the base of the connections was welded to the box columns and the UNP profiles were bolted to the beams [9]. Eight experimental specimens were tested and the results were used for calibrating the finite element modeling. The parameters under consideration were the dimensions of the UNP profiles and the end-plate. The results of this study showed that the proposed connection was of PR type and the dimensions of the end-plate and web were the most influential parameters in determining the momentrotation behavior of the connection. A simple method for determining the flexural capacity of the proposed connection was also offered.

Constructing buildings with PR connections has been previously recommended following the results of numerous studies; for instance, Maison et al. [10] considered typical 3-story and 9-story buildings with PR connections located in areas with high seismicity. They studied the seismic performance of these buildings through several nonlinear time history computer analyses. In a large experimental study, Abolmaali et al. [11] evaluated energy dissipation characteristics of 48 full-scale semi-rigid connection specimens under quasi-static cyclic loading. They concluded that the shape of hysteresis curves depended on the nonlinear interaction of connection components. However, this is not the case for hysteresis damping ratio. Braconi et al. [12] studied the seismic performance 
of low-rising frames with 24 energy dissipative semirigid connections through performing nonlinear timehistory analysis under far and near-field ground motion records. Various behavioral connection characteristics were employed. It proved that semi-rigid frames had better seismic performance than rigid frames. Attarnejad and Pirmoz [13] studied the moment and shear interaction in the numerical simulation of PR connections. Their proposed model consisted in finite element modeling of the beams and the columns. The PR connections were simulated as a discrete rotational spring, and a parallel rotational damper was utilized to capture the damping characteristics of the connection under dynamic loads. Their model showed results which were comparable to analytical examples. Brunesi et al. [14] studied the nonlinear dynamic response of four and eight-story moment-resisting frames with PR connections via performing adaptive push-over and incremental dynamic analysis. Calibrated numerical procedure, based on detailed three-dimensional solid and one-dimensional fiber-based finite element models, was utilized that accounted for material and geometric nonlinearities and the interaction among connection components via nonlinear contact algorithm.

In this paper, the performance of a proposed PR connection in steel frames is evaluated using the analytic formulations and numerical analyses [15]. First, a parametric study consisting of 35 analyses is performed on different parameters that affect the moment-rotation behavior of component-scale model related to the proposed connection by nonlinear FE modeling. Then, the initial stiffness is determined by using solid mechanics formulations. In the next step, relationships among ultimate moment, flexural rigidity, and the dimensions of different parts of the connection are presented. After that, the behavior of other proposed connection types (referred to as Type- 1 and Type- 2 in the following parts of this paper) is evaluated by performing 20 finite element analyses. Finally, the performance of proposed connection is evaluated in six representative moment-resisting portal frames by using OpenSees, with the aid of nonlinear timehistory analysis and its distributed plasticity through fiber elements. The two restrictions: preventing the formation of any plastic hinge (Collapse Prevention (CP) plastic hinge) in the columns and improving the performance level, according to ASCE41-06, are considered in these analyses. Although the results of this study support the majority of the aforementioned study results, the results specifically show that geometry and thickness of the torsional plate are the most significant parameters in determining the seismic response of the proposed PR connections. Moreover, by using PR connections, the plastic hinges can be eliminated in columns that support the preferred strong column-weak beam concept.

\section{Modeling of proposed connections}

In this part, the procedure for modeling of the proposed component-based connection is presented in details. Geometrical characteristics, material properties, element types, loads, and boundary conditions of these models are also described.

\subsection{FEM approach and assumptions}

The geometrical characteristics of the proposed component-based connection are presented in Table 1. The steel material (ST37) is assumed to be elasticperfectly plastic with yield strength and ultimate strain of $F_{y}=240 \mathrm{MPa}$ and $\varepsilon_{u}=0.35$, respectively. The modulus of elasticity and the Poisson's ratio of steel are considered $E=200 \mathrm{GPa}$ and $v=0.3$, respectively. All degrees of freedom for the connection model at end plate connecting the beam to the column are restrained. Also, increasing rotation, which results in concentrated flexural moment, is applied at the center of beam connection plate as the reference point in a ridged edge of the plate, which is shown in Figure 2(b). In the numerical model, the two free edges of the column connection plates are restrained for each of the six freedom degrees for each node. As a result, the two ends of these plates have experienced neither rotation nor displacement. Firstorder, reduced-integration quadrilateral shell elements with hour-glassing control are used. The mesh sizes of the torsional plate and other parts of the models are

Table 1. Geometrical characteristics of FEM model.

\begin{tabular}{cccc}
\hline & \multicolumn{3}{c}{ Dimensions } \\
\cline { 2 - 4 } Components & Width & Height & Thickness \\
\hline Torsional plate & 300 & 600 & 20 \\
Column connection plate & 150 & 600 & 10 \\
Beam connection plate & 150 & 600 & 20 \\
\hline
\end{tabular}
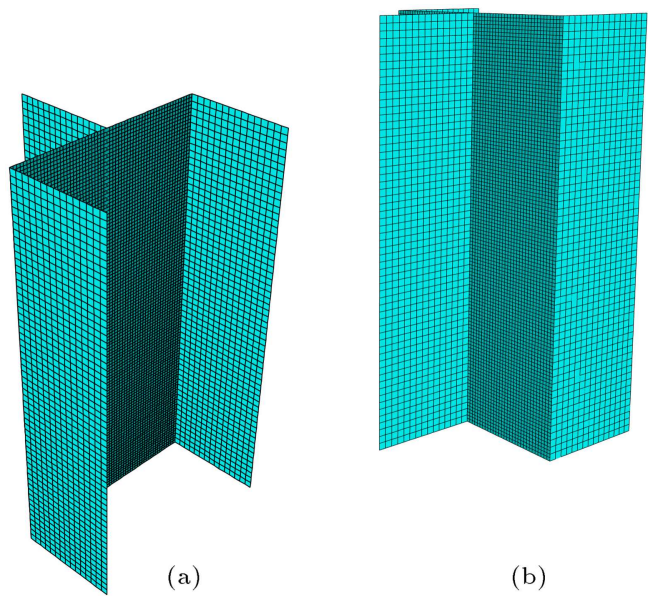

Figure 2. Views of the meshed FE model (Type-1): (a) Isometric view, and (b) side view. 


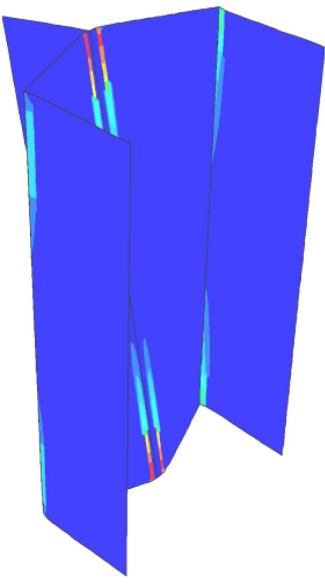

(a)

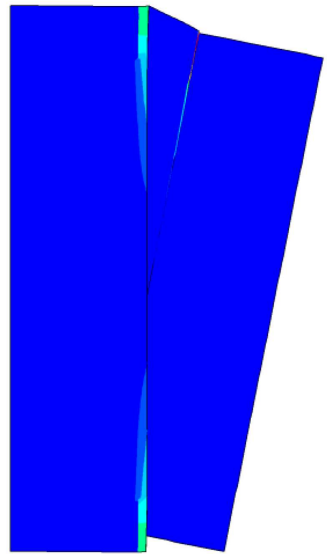

(b)
Figure 3. Maximum principal plastic strains in the proposed Type-1 connection (with red representing the ultimate strain of steel as $0.35[17]$ ): (a) Front view, and (b) side view.

$0.5 \mathrm{~cm}$ and $1 \mathrm{~cm}$, respectively. The Newton-Raphson method is implemented to perform static analysis in the commercial software Abaqus [16], which takes material and geometric nonlinearities into account. The meshed model of the proposed component-based connection is shown in Figure 2.

The results for one of the proposed connections in terms of maximum principal plastic strain are shown in Figure 3. As it can be seen, the damage concentration occurs adjacent to the beam connection plate and above the torsional plate. It is noted that by yielding the elements located at the edge of the torsional plate (as shown in Figure 3), stiffness softening in the moment-rotation behavior is initiated.

\subsection{Verification of FEM}

In order to verify the accuracy of the FEM, solid mechanics formulations are used for determining the elastic rigidity of the proposed component-based connection. For this work, the connection is divided into several strips with width of $0.5 \mathrm{~cm}$, as shown in Figure 4(a). Note that the applied flexural moment at the beam connection plate is substituted by a coupled force in the analytical model, hereafter, shown in this figure. A single typical strip is also shown in Figure 4(b). Because of the rotation compatibility at both parts in Figure 4, Eq. (1) is concluded:

$$
\frac{M l_{3}}{4 E I_{3}}=\frac{\left(\frac{F}{2}\right) \times\left(\frac{l_{2}}{2}\right)^{2}}{2 E I_{2}}-\frac{M l_{2}}{2 E I_{2}} .
$$

The moment at the mid-length of each strip (shown in Figure 4(c)) is:

$$
M=\frac{F l_{2}^{2}}{4 l_{3} \times \frac{I_{2}}{I_{3}}+8 l_{2}} .
$$

By implementing Eq. (4), which is derived from Eq. (3), the relation between the applied force and the resulting displacement is determined. According to this equation, the resultant moment related to first element yielding is calculated as 26897 N.m. Note that this moment is the result of the summation of the generated forces at each strip (Figure 4(a)) multiplied by its arm of coupled force. According to Figure 5, obtained from nonlinear FEM analysis of the model presented in Section 2.1, the moment related to the first yielding of elements is $25795 \mathrm{~N} . \mathrm{m}$, which proves the accuracy of FEM method and assumptions:

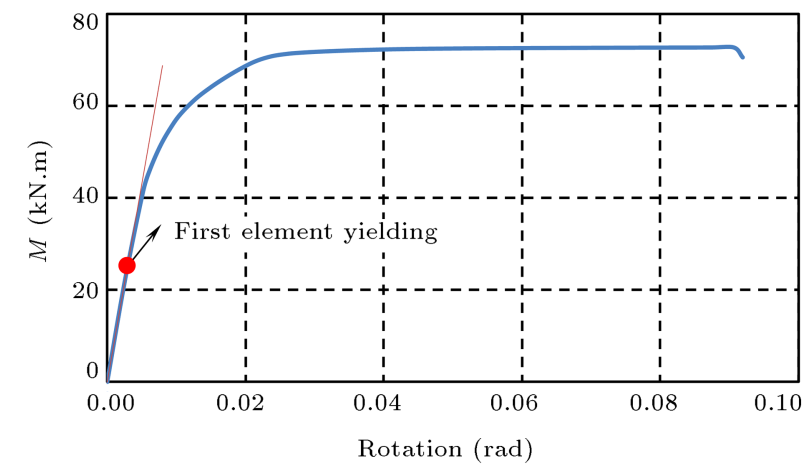

Figure 5. Moment-rotation of the proposed Type-1 connection.

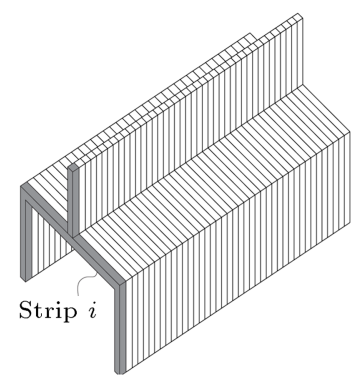

(a)

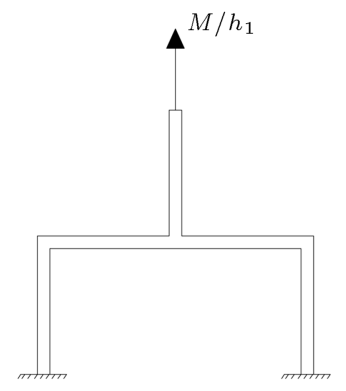

(b)

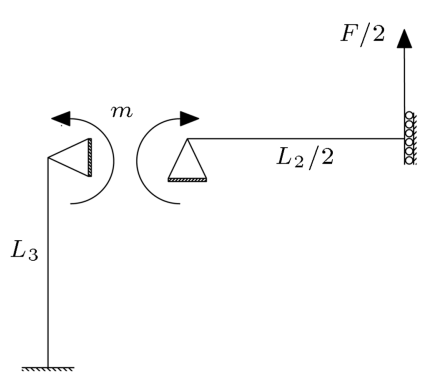

(c)

Figure 4. The free-body diagram of the strips in the proposed Type-1 connection: (a) Meshed connection; (b) $i$-th strip, and (c) free-body diagram of the $i$-th strip. 


$$
\begin{aligned}
& F \times \delta= \int_{0}^{l_{1}} \frac{N_{1}^{2}}{2 E A_{1}} d x+\int_{0}^{l_{1}} \frac{M_{1}^{2}}{2 E I_{1}} d x \\
&+\int_{0}^{l_{1}} \frac{f_{s} \times V_{1}^{2}}{2 G A_{1}} d x+\int_{0}^{l_{2}} \frac{N_{2}^{2}}{2 E A_{2}} d x \\
&+\int_{0}^{l_{2}} \frac{M_{2}^{2}}{2 E I_{2}} d x+\int_{0}^{l_{2}} \frac{f_{s} \times V_{2}^{2}}{2 G A_{2}} d x \\
&+\int_{0}^{l_{3}} \frac{N_{3}^{2}}{2 E A_{3}} d x+\int_{0}^{l_{3}} \frac{M_{3}^{2}}{2 E I_{3}} d x \\
&+\int_{0}^{l_{3}} \frac{f_{s} \times V_{3}^{2}}{2 G A_{3}} d x \\
& F=\frac{\delta}{3.21 \times 10^{-7}} .
\end{aligned}
$$

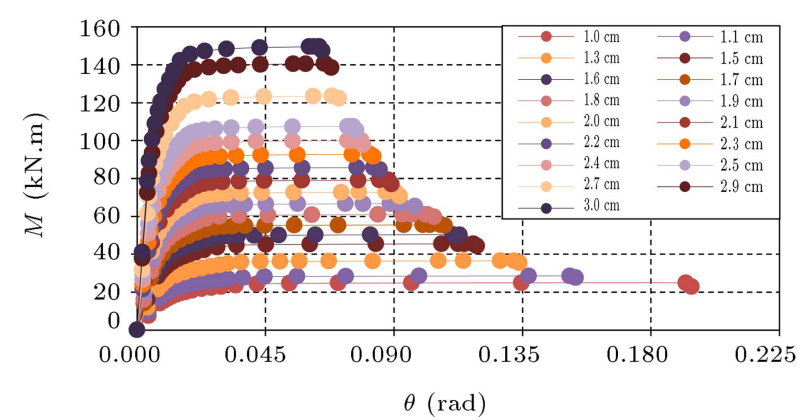

(a)

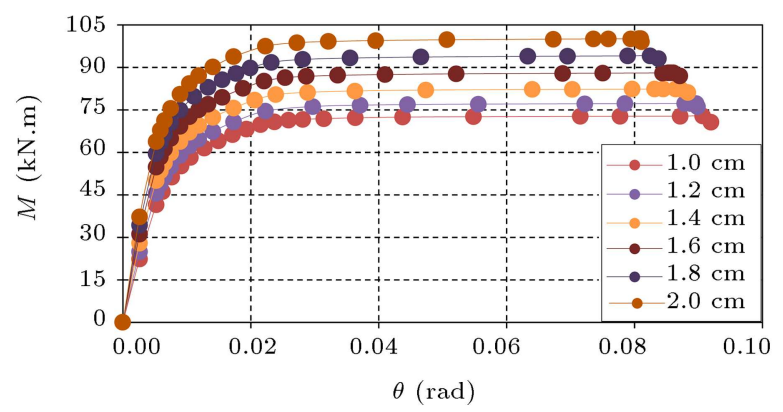

(c)

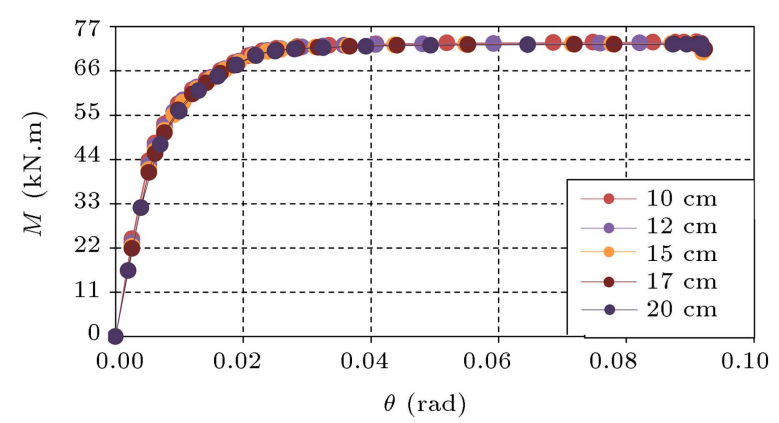

(e)

\section{Parametric study of the proposed connections}

\subsection{Type 1 of the proposed connection}

In this part, the effects of the dimensions of the proposed connection's different parts are evaluated via $39 \mathrm{FE}$ analyses. In all models, the dimensions for different parts of connection are in accordance with Table 1. The results of parametric study are presented in Figure 6. According to Figure 6(a), as the thickness of the torsional plate increases, ductility capacity of the proposed connection decreases. The ductility capacity of the studied models is calculated by dividing the ultimate rotation of the models to that of the yielding. The former is determined when there is strength softening in the moment-rotation response (as shown in Figure 6), which is accompanied by exceeding

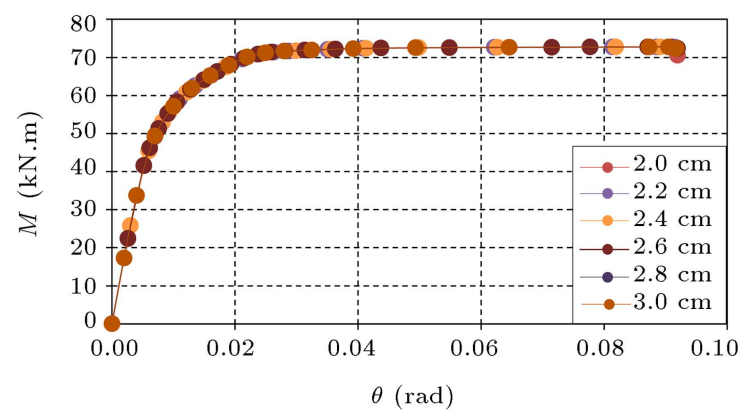

(b)

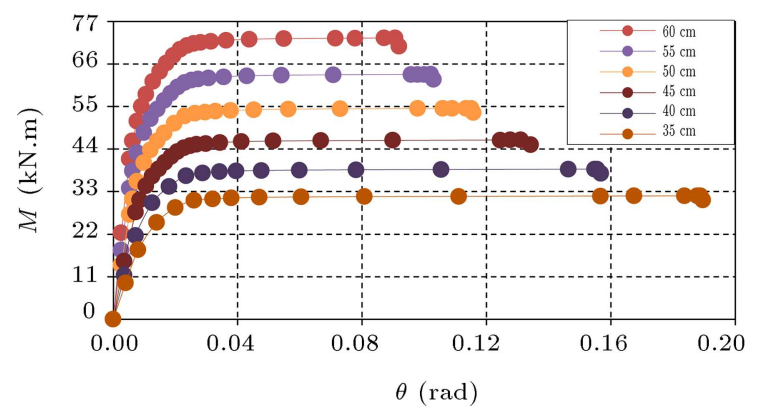

(d)

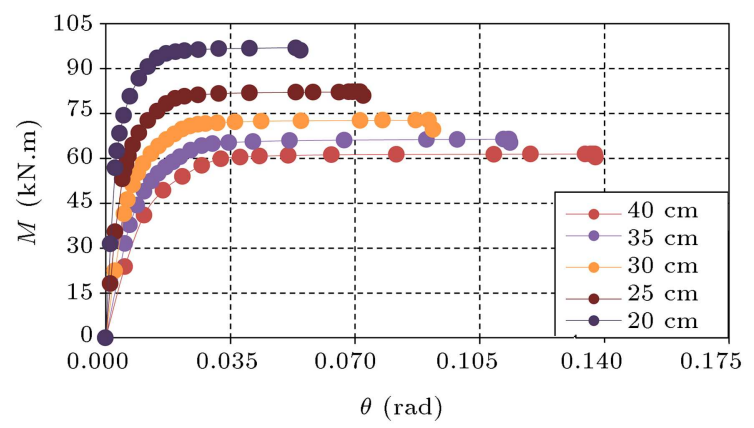

(f)

Figure 6. Moment-rotation curve of the models: (a) The effects of thickness of torsional plate, (b) the effects of thickness of beam connection plate, (c) the effects of thickness of column connection plate, (d) the effects of total height of connection, (e) the effects of widths of beam and column connection plates, and (f) the effects of width of torsional plate. 
the maximum plastic strain of the model parts in the considered ultimate strain of the material (red color in Figure 3 ). The latter rotation is determined by idealizing the moment-rotation response by an equivalent bilinear curve according to ASCE41-06. According to Figure 6(b), it is observed that thickness of the beam connection plate has no considerable influence on the behavior of connection. The results for the thickness of the column connection plate shown in Figure 6(c) indicate that increasing the thickness has the same effects as increasing the thickness of torsional plate, albeit to a lesser degree. Note that since the beam connection plate does not experience any nonlinearity, variation in thickness of this plate has no effect on the capacity of the connection. This is not the case in column connection plate, which has a similar behavior to a single-story frame beside the torsional plate, and, therefore, increasing the thickness of this plate has a direct effect on the initial stiffness and strength of the connection. The effects of connection height are shown in Figure 6(d). The effects clearly prove that decreasing the height of connection leads to ductile behavior. Although the positive effects of increasing connection height are obvious, the sensitivity of the proposed connection to each of the considered parameters is important so that they can be included in the proposed relations in the next part of this paper.

As the results indicated in Figure 6(e) suggest, the widths of beam and the column connection plates have no considerable influence on the behavior of the proposed connection. Figure $6(\mathrm{f})$ illustrates that decreasing the width of the torsional plate results in more ductility in the behavior of the proposed connection. In addition to the above results, in all cases, as the flexural rigidity increases, the ultimate moment capacity increases.

\subsection{Type 2 of the proposed connection}

In the case in which the height of the beam is smaller than the height of the connecting plate, Type- 2 connection is proposed, which is schematically shown in Figure 7. In response to this need, the influence of reducing the height of beam connection plate is evaluated in this part. Figure 8 shows that decreasing

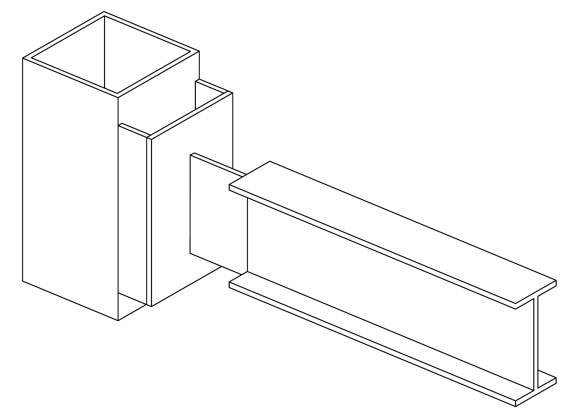

Figure 7. Schematic representation of the proposed Type-2 connection. the height of beam connection plate up to $10 \mathrm{~cm}$ shorter than the total height of the connection does not have any considerable influence on the behavior of the connection. In addition to the above results, the ultimate moment resistance and initial flexure rigidity decrease by reducing the height of beam connection plate.

Moreover, parametric studies on the height of the connection ranging from $35 \mathrm{~cm}$ to $55 \mathrm{~cm}$ have been conducted. The studies reveal that connections in which the height of connection plate is less than the height of connection by not less than $10 \mathrm{~cm}$ show a similar behavior to the connections with larger height of connection plate. Therefore, the formulations for determination of initial stiffness and moment capacity derived from Type- 1 connection can be used for Type2 connection as well, provided that the aforementioned height limits are satisfied.

\section{Proposed relation for initial flexural rigidity and ultimate moment capacity}

In this part, formulations are offered that determine the initial stiffness of each connection part based on the regression analysis presented in Figure 6. In doing so, the less important parameters (i.e., the thickness of the beam connection plate (part (b) of this figure)) and the widths of beam and column connection plates (part (e) of this figure) are excluded from the formulation. In the next part, the assumptions of frame models for performing nonlinear dynamic analysis, the details of modeling of the considered different connection types, and the frame members are elaborated.

\subsection{Formulations}

The results of parametric study are used in the current linear regression analysis in order to develop relations between dimensions of different parts of the proposed connection, initial flexural rigidity, and ultimate moment capacity. To this end, each part of the proposed connection is replaced by an equivalent spring. According to Figure 9, the column connection plates are parallel springs while they constitute series of springs with the torsional plate and the beam connection plate. The flexural rigidity of each column's connection plate is calculated using Eq. (5). Because the two column connection plates are parallel springs, the total flexural rigidity of these parts is determined by Eq. (6). Moreover, the flexural rigidity of the beam connection plate is in accordance with Eq. (7):

$$
\begin{aligned}
& K_{1}=\alpha_{1} \times \frac{E\left(\frac{t_{3} h_{3}^{3}}{12}\right)}{l_{3}^{2}}, \\
& K_{2}=2 \times K_{1}=a_{2} \times \frac{E\left(\frac{t_{3} h_{3}^{3}}{12}\right)}{l_{3}^{2}},
\end{aligned}
$$




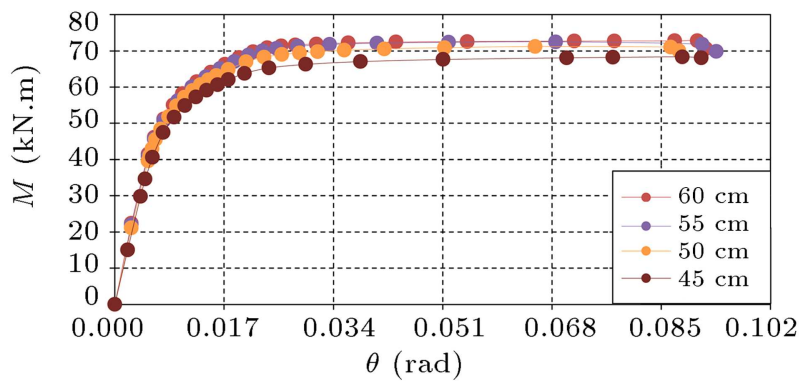

(a)

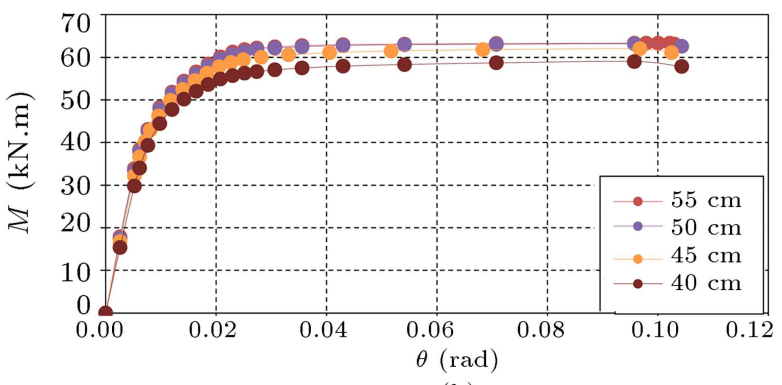

(b)

Figure 8. Moment-rotation curve (the height of beam connection plate is variable): (a) Total height of $60 \mathrm{~cm}$, and (b) total height of $55 \mathrm{~cm}$.

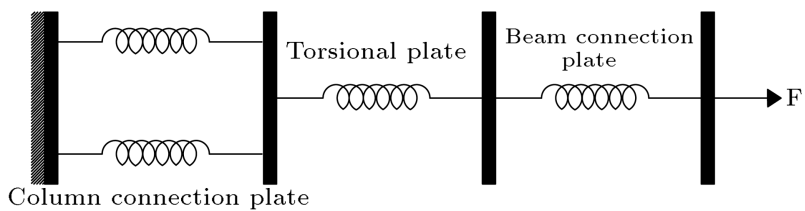

Figure 9. Substitution of different connection components with equivalent springs.

$$
K_{3}=\alpha_{3} \times \frac{E\left(\frac{t_{1} h_{1}^{3}}{12}\right)}{l_{1}^{2}} .
$$

Speaking of the torsional plate, all the strips of this part are parallel springs and the flexural rigidity of the torsional plate is in accordance with Eq. (8). Because $K_{2}, K_{3}$, and $K_{4}$ are springs in series, the total flexural rigidity of the proposed connection is in accordance with Eq. (10). Note that in this equation, parameters "A," "B," and "C" are the inverse stiffness values derived from Eqs. (5)-(7) based on the concept of springs in series. Constant coefficients are determined by linear regression analysis with R-square factor of 0.979. Table 2 presents the comparison of the predicted initial flexural rigidity with that of parametric FE analysis. The models in Table 2 are not included in the regression analysis. Moreover, based on the regression analysis with R-square factor of 0.982 , the ultimate moment capacity can be determined based on Eq. (11). In this equation, the constant coefficients are based on the regression analysis and the power of each of the parameters "A," "B," and "C" is based on the trial and error process with the aim of minimizing the $\mathrm{R}$ square factor. The differences between the predicted ultimate moment capacity of the proposed connection and those of parametric FE analyses are presented in Table 3. In all the equations below, the units are $N$ and $m$ :

$$
\begin{aligned}
K_{4}= & \left(a_{4} \times \frac{E I_{b 2}}{l_{2}^{3}}\right)+\left(a_{5} \times \frac{E I_{b 2}}{l_{2}^{3}}\right) \\
& +\left(a_{6} \times \frac{E I_{b 2}}{l_{2}^{3}}\right)+\ldots+\left(a_{n} \times \frac{E I_{b 2}}{l_{2}^{3}}\right) \\
& =a_{i} \times \frac{E I_{b 2}}{l_{2}^{3}}
\end{aligned}
$$

where:

$$
\begin{aligned}
& I_{b 2}=\frac{t_{2}^{3}}{2400}, \\
& K= \\
& \frac{1}{\left(5.86 \times 10^{-9}\right) A+\left(3.67 \times 10^{-10}\right) B+\left(1.84 \times 10^{-11}\right) C}, \\
& A=\frac{l_{3}^{2}}{t_{3} \times h_{3}^{3}}, \quad B=\frac{l_{1}^{2}}{t_{1} \times h_{1}^{3}}, \quad C=\frac{l_{2}^{2}}{t_{2}^{3}}, \\
& M_{u}=\frac{1}{\left(5.92 \times 10^{-8}\right) A+\left(-1.97 \times 10^{-4}\right) B+\left(2.70 \times 10^{-9}\right) C}, \\
& A=\frac{L_{3}^{1.5}}{t_{3}^{1.3} \times h_{3}^{3}}, \quad B=\frac{L_{1}^{4.4}}{t_{1}^{0.5} \times h_{1}^{3}}, \quad C=\frac{L_{2}^{1.3}}{t_{2}^{2.4}} .
\end{aligned}
$$

\subsection{Modeling approach and assumptions}

The selected example frames represent the most critical frame in a symmetrical 3D frame building in terms of demands to capacity ratio. The residential building is assumed to be located in Tehran with a very high seismicity according to Iranian Code of Practice for Seismic Design of Buildings (Standard 2800 [18]). The

Table 2. Comparison of initial flexural rigidity of FE analysis and the proposed relation.

\begin{tabular}{ccccccc}
\hline Model & $\boldsymbol{t}_{\mathbf{1}}(\mathbf{m})$ & $\boldsymbol{t}_{\mathbf{2}}, \boldsymbol{t}_{\mathbf{3}}(\mathbf{m})$ & $\boldsymbol{L}_{\mathbf{1}}, \boldsymbol{L}_{\mathbf{2}}(\mathbf{m})$ & $\boldsymbol{L}_{\mathbf{3}}(\mathbf{m})$ & $\boldsymbol{h}_{\mathbf{1}}, \boldsymbol{h}_{\mathbf{2}}, \boldsymbol{h}_{\mathbf{3}}(\mathbf{m})$ & $\boldsymbol{e}(\boldsymbol{\%})$ \\
\hline 1 & 0.01 & 0.02 & 0.15 & 0.30 & 0.60 & 7.0 \\
2 & 0.01 & 0.02 & 0.15 & 0.30 & 0.50 & 2.0 \\
3 & 0.01 & 0.02 & 0.12 & 0.30 & 0.60 & 6.0 \\
\hline
\end{tabular}


Table 3. Comparison of the ultimate moment capacity of FE analysis and the proposed relation.

\begin{tabular}{|c|c|c|c|c|c|c|c|}
\hline Model & $t_{1}(\mathrm{~m})$ & $t_{2}(\mathrm{~m})$ & $t_{3}(\mathrm{~m})$ & $L_{1}, L_{2}(\mathrm{~m})$ & $L_{3}(\mathbf{m})$ & $h_{1}, h_{2}, h_{3}(\mathrm{~m})$ & $e(\%)$ \\
\hline 1 & 0.010 & 0.020 & 0.020 & 0.150 & 0.300 & 0.600 & 5.0 \\
\hline 2 & 0.010 & 0.020 & 0.021 & 0.150 & 0.300 & 0.600 & 6.6 \\
\hline 3 & 0.010 & 0.020 & 0.022 & 0.150 & 0.300 & 0.600 & 8.4 \\
\hline 4 & 0.010 & 0.020 & 0.023 & 0.150 & 0.300 & 0.600 & 10.4 \\
\hline 5 & 0.010 & 0.020 & 0.024 & 0.150 & 0.300 & 0.600 & 12.6 \\
\hline 6 & 0.010 & 0.020 & 0.019 & 0.150 & 0.300 & 0.600 & 3.8 \\
\hline 7 & 0.010 & 0.020 & 0.018 & 0.150 & 0.300 & 0.600 & 3.1 \\
\hline 8 & 0.010 & 0.020 & 0.017 & 0.150 & 0.300 & 0.600 & 7.0 \\
\hline 9 & 0.010 & 0.020 & 0.016 & 0.150 & 0.300 & 0.600 & 3.3 \\
\hline 10 & 0.010 & 0.020 & 0.015 & 0.150 & 0.300 & 0.600 & 4.3 \\
\hline 11 & 0.010 & 0.020 & 0.013 & 0.150 & 0.300 & 0.600 & 8.7 \\
\hline 12 & 0.010 & 0.020 & 0.011 & 0.150 & 0.300 & 0.600 & 16.1 \\
\hline 13 & 0.010 & 0.020 & 0.010 & 0.150 & 0.300 & 0.600 & 21.1 \\
\hline 14 & 0.010 & 0.020 & 0.020 & 0.150 & 0.300 & 0.600 & 5.0 \\
\hline 15 & 0.010 & 0.022 & 0.020 & 0.150 & 0.300 & 0.600 & 5.6 \\
\hline 16 & 0.010 & 0.024 & 0.020 & 0.150 & 0.300 & 0.600 & 6.1 \\
\hline 17 & 0.010 & 0.026 & 0.020 & 0.150 & 0.300 & 0.600 & 6.6 \\
\hline 18 & 0.010 & 0.028 & 0.020 & 0.150 & 0.300 & 0.600 & 6.9 \\
\hline 19 & 0.010 & 0.030 & 0.020 & 0.150 & 0.300 & 0.600 & 7.3 \\
\hline 20 & 0.010 & 0.020 & 0.020 & 0.150 & 0.300 & 0.600 & 5.0 \\
\hline 21 & 0.012 & 0.020 & 0.020 & 0.150 & 0.300 & 0.600 & 1.0 \\
\hline 22 & 0.014 & 0.020 & 0.020 & 0.150 & 0.300 & 0.600 & 3.9 \\
\hline 23 & 0.016 & 0.020 & 0.020 & 0.150 & 0.300 & 0.600 & 4.0 \\
\hline 24 & 0.018 & 0.020 & 0.020 & 0.150 & 0.300 & 0.600 & 3.5 \\
\hline 25 & 0.020 & 0.020 & 0.020 & 0.150 & 0.300 & 0.600 & 1.9 \\
\hline 26 & 0.010 & 0.020 & 0.020 & 0.150 & 0.300 & 0.600 & 5.0 \\
\hline 27 & 0.010 & 0.020 & 0.020 & 0.150 & 0.300 & 0.550 & 2.8 \\
\hline 28 & 0.010 & 0.020 & 0.020 & 0.150 & 0.300 & 0.500 & 2.5 \\
\hline 29 & 0.010 & 0.020 & 0.020 & 0.150 & 0.300 & 0.450 & 4.6 \\
\hline 30 & 0.010 & 0.020 & 0.020 & 0.150 & 0.300 & 0.400 & 9.9 \\
\hline 31 & 0.010 & 0.020 & 0.020 & 0.150 & 0.300 & 0.350 & 18.5 \\
\hline 32 & 0.010 & 0.020 & 0.020 & 0.100 & 0.300 & 0.600 & 9.4 \\
\hline 33 & 0.010 & 0.020 & 0.020 & 0.120 & 0.300 & 0.600 & 2.0 \\
\hline 34 & 0.010 & 0.020 & 0.020 & 0.150 & 0.300 & 0.600 & 5.0 \\
\hline 35 & 0.010 & 0.020 & 0.020 & 0.170 & 0.300 & 0.600 & 6.3 \\
\hline 36 & 0.010 & 0.020 & 0.020 & 0.200 & 0.300 & 0.600 & 0.18 \\
\hline 37 & 0.010 & 0.020 & 0.020 & 0.150 & 0.400 & 0.600 & 11.3 \\
\hline 38 & 0.010 & 0.020 & 0.020 & 0.150 & 0.350 & 0.600 & 7.9 \\
\hline 39 & 0.010 & 0.020 & 0.020 & 0.150 & 0.300 & 0.600 & 5.0 \\
\hline 40 & 0.010 & 0.020 & 0.020 & 0.150 & 0.250 & 0.600 & 4.0 \\
\hline
\end{tabular}




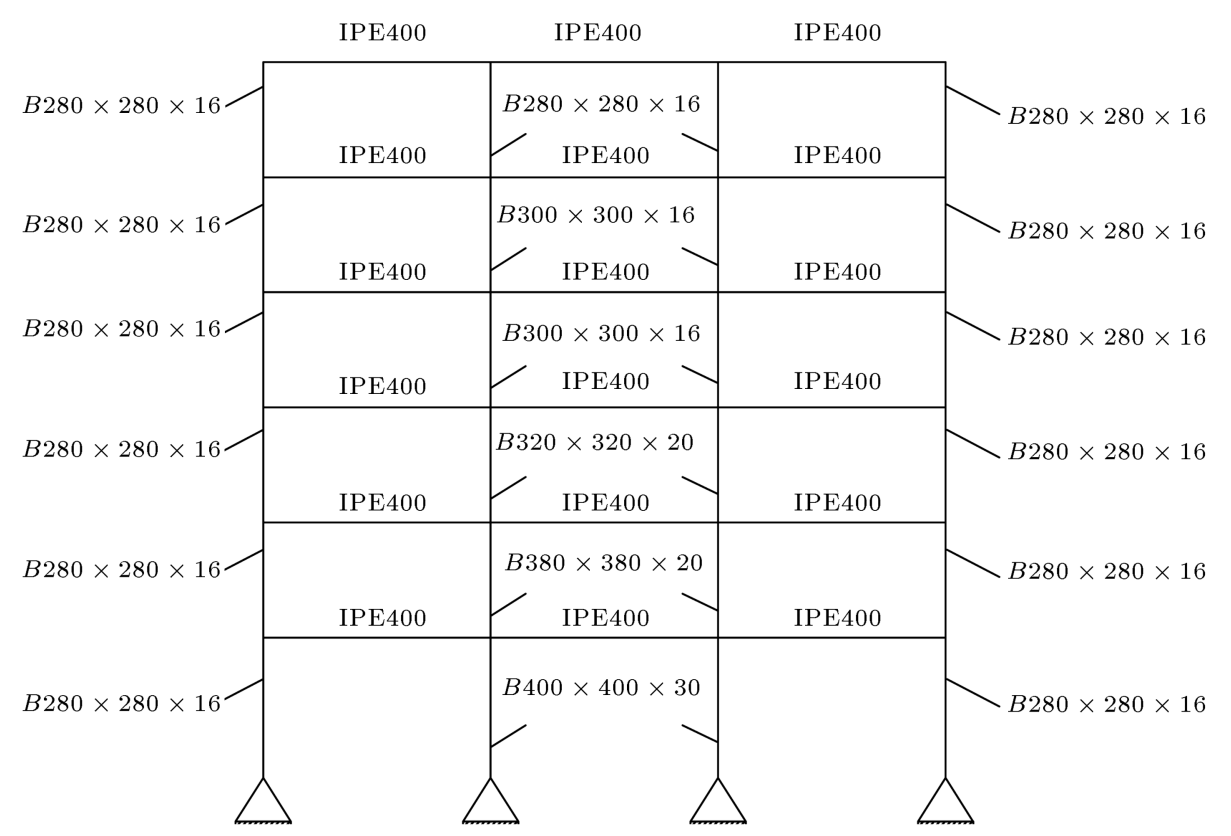

Figure 10. Considered portal frame model (the column section represents a square box with the width and the thickness of $280 \mathrm{~mm}$ and $16 \mathrm{~mm}$, respectively.).

considered portal frame, as depicted in Figure 10, is a 6-story (all heights are $3 \mathrm{~m}$ ) 3-span building (all spans are $6 \mathrm{~m}$ ) intermediate-moment resisting frame located on soil Type 3 based on ASCE 710 [19], which is designed in accordance with AISC 360 [20]. It should be noted that one of the main differences between special and intermediate momentresisting frames according to AISC 360 is the concept of strong column-weak beam, which is mandatory in the former frames. The considered dead load and live load are $400 \mathrm{kgf} /$ and $200 \mathrm{kgf} /$, respectively. In order to compare the performance of proposed connection in this frame with the performance of rigid and pin connections, six variations of the considered frame are modeled in OpenSees. The differences of these models are in the types of their connections and the location of each connection type. Table 4 presents the details of each of the above-mentioned models. Note that the geometrical characteristics of the considered PR connection in part 5 of this paper (example frame models by OpenSees) are exactly the same as the ones presented in Table 1, except for the thickness of torsional plate, which is considered equal to $2.9 \mathrm{~cm}$. This results in a moment capacity of $139 \mathrm{kN} . \mathrm{m}$ and the initial stiffness of $22.02 \mathrm{MN}$.m, which are shown in Figures 6(a) and 11.

The AISC Specification [20] proposes a dimensionless parameter " $a$ " as $K_{s} L / E I$ in which $K_{s}$ is the secant stiffness of the connection, and $L$ and $E I$ are the length and flexural rigidity of the beam, respectively. If " $a$ " is larger than 20 , the connection is fully restrained and if " $a$ " is smaller than 2 , the connection is deemed to be pin. The connection is partially restrained (semi-
Table 4. Different details of considered frames.

\begin{tabular}{ccc}
\hline Frame type & $\begin{array}{c}\text { Outer-span } \\
\text { connection }\end{array}$ & $\begin{array}{c}\text { Inner-span } \\
\text { connection }\end{array}$ \\
\hline F1 & FR & FR \\
F2 & PR & PR \\
F3 & FR & PR \\
F4 & PR & FR \\
F5 & PR & Pin \\
F6 & Pin & PR \\
\hline
\end{tabular}

rigid) if " $a$ " is between 2 and 20. In the present study, this value is 2.85 for PR connection, which is close to the pin connection.

These models have been chosen for analysis in order to determine the optimum type and arrangement of connections in the studied portal frame. The modeling details of PR connections in this study follow the procedure in [21]. As shown in Figure 11, the effects of PR connection are considered by defining two zero-length elements with coupled displacement. The considered hysteresis curve for the proposed connection is elasto-perfectly plastic, as shown in Figure 11. This means that the unloading path follows the same stiffness as the loading path without any stiffness degradation resulting from damage in the material, which is in line with Saritas and Koseoglu [22] observation. The general shape of the hysteresis behavior for the proposed PR connection is in accordance with some 

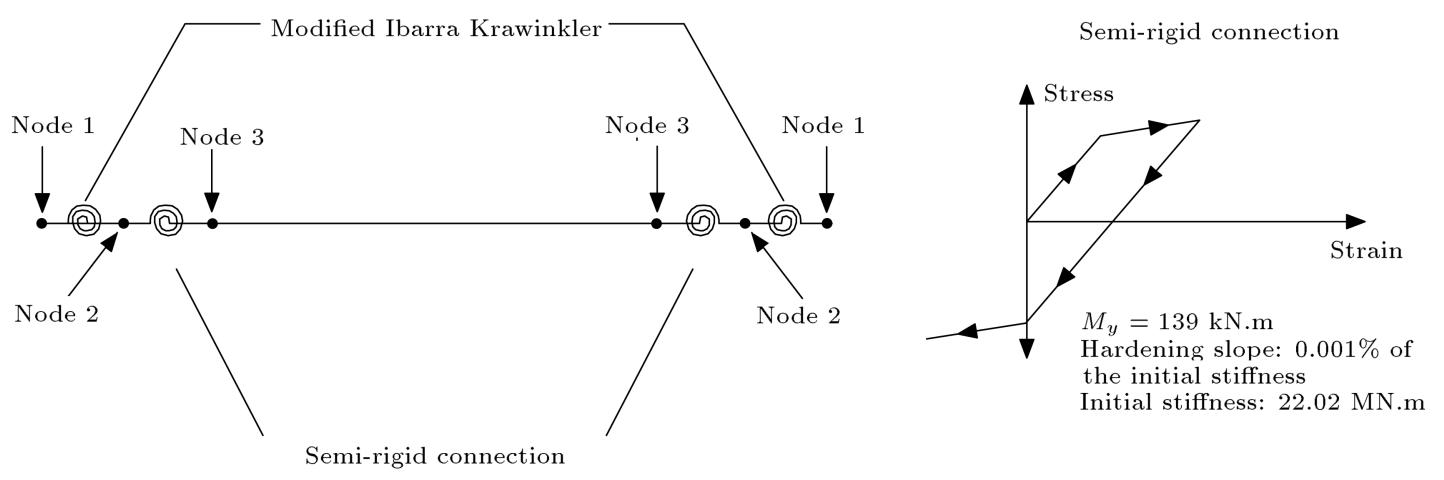

Figure 11. Behavior and locations of plastic hinges in PR connections.

Table 5. Natural periods of considered frames.

\begin{tabular}{cccccccc}
\hline \multirow{2}{*}{ Modes } & \multicolumn{6}{c}{ Frame types natural period (sec) } \\
\cline { 2 - 7 } & F1 & F2 & F3 & F4 & F5 & F6 \\
\hline 1 & 1.11 & 1.79 & 1.23 & 1.43 & 2.15 & 2.97 \\
2 & 0.33 & 0.49 & 0.37 & 0.42 & 0.55 & 0.69 \\
3 & 0.17 & 0.23 & 0.18 & 0.2 & 0.24 & 0.28 \\
\hline
\end{tabular}

numerically adopted and experimental results of PR connections $[10,12,23]$.

The results of performing modal analysis on the frames under study are presented in Table 5 . As it is clear, negligible differences exist between the OpenSees [24] models and the corresponding example frames modeled in SAP2000 [25]. The frame members in OpenSees and SAP2000 are modeled by linear elastic elements since they are only used for modal analysis. However, in OpenSees, the nonlinearity of the material is taken into account by defining a hinge at each member's end according to the IbarraKrawinkler model [26,27] (the parameters are shown in Table 6) for beam members, which have been previously calibrated for various behavioral characteristics of beam-to-column connections. For column members, the nonlinearity of the material is simulated via distributed-plasticity by using fiber-element formulation.

\section{Nonlinear dynamic analysis}

In order to evaluate the seismic response of the proposed PR connection in moment-resisting frames, nonlinear time-history analyses are performed. Then, the results of model building in terms of each plastic hinge rotation are compared with those of the corresponding models with other types of connections (i.e., "FR" and "Pin"). In this part, the aforementioned frames are analyzed under three scaled records in accordance with ASCE41-06 [2]. The selected far-field records, which are presented in Table 7 , are found in FEMA P-695 [28]. The purpose of these analyses is evaluating the formation of plastic hinges with the hope of preventing the formation of any plastic hinges in columns at $\mathrm{CP}$ performance level with the aid of the proposed PR connection. Furthermore, another target of these analyses is increasing the performance

Table 6. Ibarra-Krawinkler parameters.

\begin{tabular}{|c|c|c|c|c|c|c|c|}
\hline$M_{c} M_{y}$ & $\begin{array}{l}L S, L K \\
L A, L D\end{array}$ & $\begin{array}{l}C S, C K, \\
C A, C D\end{array}$ & $\begin{array}{l}t h \_P p \\
t h \_P N\end{array}$ & $\begin{array}{l}t h \_P c P, \\
t h \_P c N\end{array}$ & $\begin{array}{l}\operatorname{Res} P, \\
\operatorname{Res} N\end{array}$ & $\begin{array}{l}t h_{-} u P \\
t h_{\_} u N\end{array}$ & $\begin{array}{l}D P, \\
D N\end{array}$ \\
\hline 1.05 & 1000 & 1.00 & 0.02 & 0.16 & 0.40 & 0.40 & 1.00 \\
\hline
\end{tabular}

Table 7. Considered records for nonlinear dynamic analysis.

\begin{tabular}{|c|c|c|c|c|}
\hline \multirow[b]{2}{*}{ ID no. } & \multicolumn{3}{|c|}{ Earthquake } & \multirow[b]{2}{*}{ Recording station } \\
\hline & $M$ & Year & Name & \\
\hline 1 & 6.6 & 1971 & San Fernando & LA-Hollywood Store \\
\hline 2 & 7.5 & 1999 & Kocaeli & Arcelik \\
\hline 3 & 7.1 & 1999 & Hector Mine & Hector \\
\hline
\end{tabular}




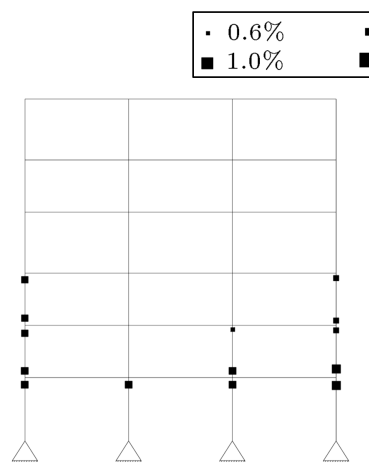

(a)

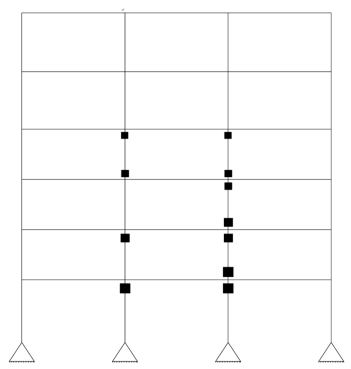

(c)
$0.8 \%=0.9 \%$

$1.2 \%$

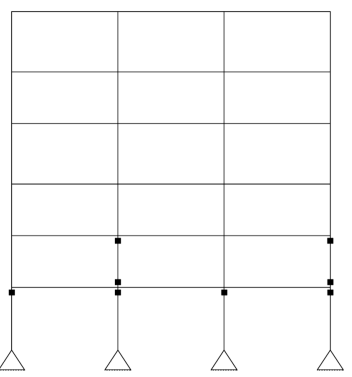

(b)

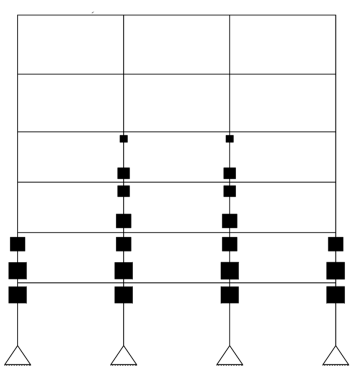

(d)
Figure 12. Joint rotations in representative portal frames: (a) Column hinges in F1, (b) column hinges in F3, (c) column hinges in F4, and (d) column hinges in F5.

level of considered frames by utilizing the proposed PR connection.

Formation of plastic hinges in the columns of considered frames for the records with the worst results is shown in Figure 12. Note that the allowable hinge rotation in these figures is based on recommendation of ASCE41-06 for the CP performance level. As observed, the joint column rotation in all frames is larger than CP level of allowable rotation, except for the frame with PR connection (model F2) that, hence, experiences hinge mechanism under the applied earthquakes. Note that in the model with PR connections (model F2), no single hinge rotation becomes larger than the rotation in the $\mathrm{CP}$ performance level. This is mainly because by using this type of connection, the moment transfer between the beams and columns is controlled, while the drift ration of all the stories below the recommended maximum is maintained by ASCE41-06. On the other hand, the hinge rotation in the models becomes lager than CP performance level. In some cases, this phenomenon leads to a soft story mechanism.

Since model F6 is more flexible than model F5 due to having more pin connections, it definitely experiences collapse, considering the collapse of model F5; therefore, the results of model $\mathrm{F} 6$ are not mentioned here for brevity. It is concluded that the frame with the proposed PR connection has the most acceptable performance without requiring increase in the size of column and beam sections. Moreover, the maximum drift ratio in this frame is smaller than the allowable drift ratio of $5 \%$ as for the $\mathrm{CP}$ performance level. As can be seen in this figure, the hinge rotation in model F5 is larger than those in all other models (except for model F6).

A design procedure for determination of different parts of the proposed connections (Type- 1 and Type2 ) is presented in the form of a flowchart in Figure 13. According to this procedure, the initial design of the structure is based on the intermediate momentresisting frame via linear static analysis. Then, considering all connections as PR, the frame is upgraded to a special moment-resisting frame.

\section{Conclusions}

According to the results of this paper, the following conclusions are made:

- The geometry of torsional plate, especially its thickness, is the most influential parameter for determination of the proposed PR connection's behavior. Therefore, the response of structures can be easily adjusted in the design procedure by proper selection of the torsional plate thickness. Other influential parameters are connection height, the thickness of the column connection plate, and the width of the torsional plate. According to Figure 8, the height of beam connection plate can be reduced to $15 \mathrm{~cm}$ shorter than the connection height if practical restrictions are applied. Since there is no major change in the behavior of the proposed connection, the relations in this paper can be utilized for designing the initial stiffness and strength of the PR connections;

- By performing nonlinear, time-history analysis, it is shown that the frame with the proposed PR connection has the most acceptable seismic performance without requiring an increase in the size of columns and beam sections;

- If the special moment-resisting frame is considered as a seismic resistant system, the structure with PR connection can be designed to prevent formation of plastic hinges in columns and, thus, there is no need to design it due to strong column-weak beam restriction;

- According to the proposed flowchart in Figure 13, the designer can initially design the structure assuming the intermediate moment-resisting frame system. Then, the system is upgraded to the special moment-resisting frame by the proposed optimum arrangements of the $\mathrm{PR}$ connections in designed structure. In doing so, it is expected that no plastic hinge would be initiated at any columns in the designed-level seismic actions. 


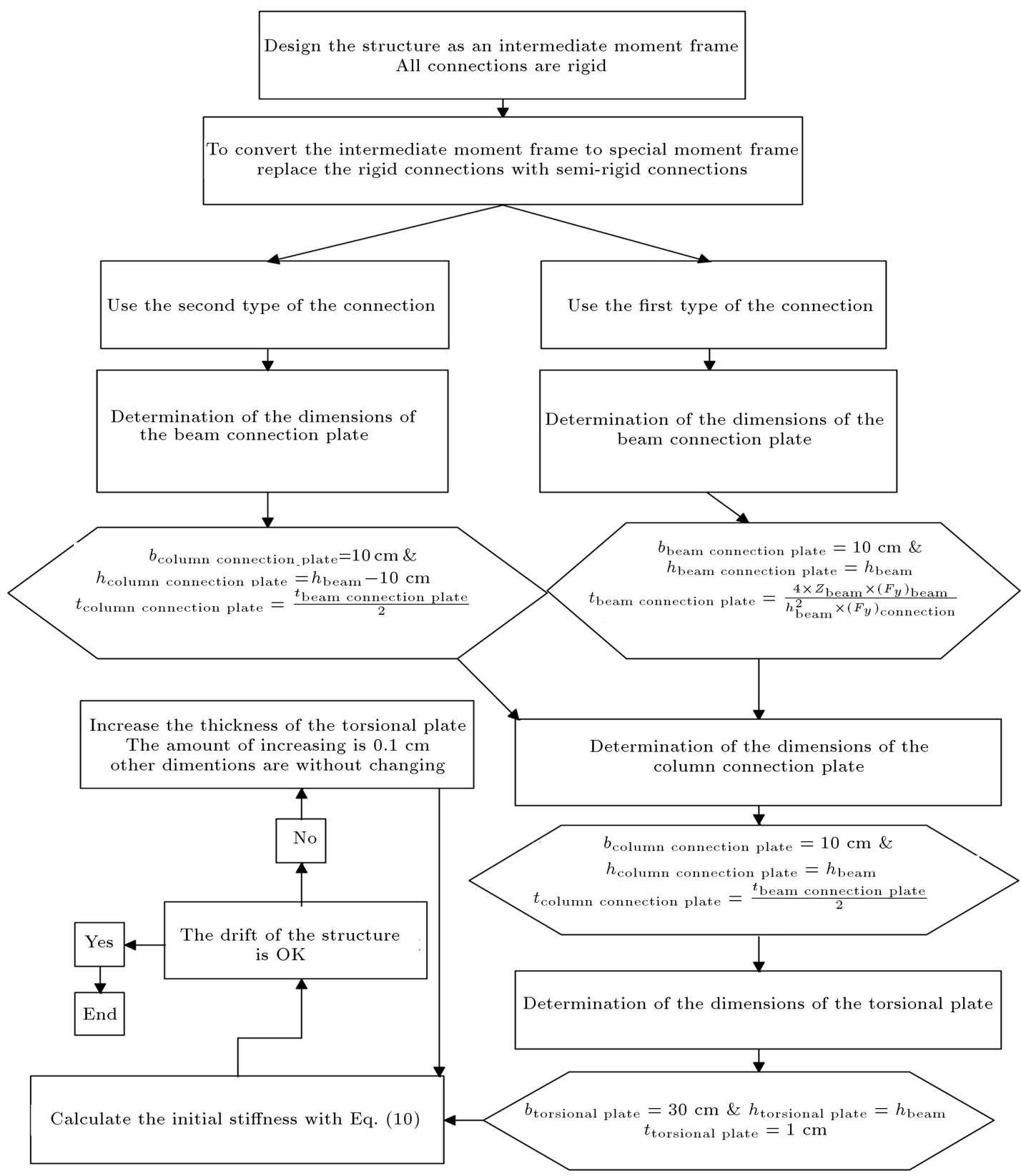

Figure 13. Design flowchart of the proposed connection by intermediate moment-resisting frame to special moment-resisting frame with PR connections.

\section{Nomenclature}

$A_{1}$

$A_{2}$

$A_{3}$

$C A$

$C D$

$C K$
The cross section of the strip of beam connection plate

The cross section of the strip of torsional plate

The cross section of the strip of column connection plate

Exponent for accelerated reloading

stiffness deterioration

Exponent for post-capping strength

deterioration

$C S$

$D N$

$D P$

Exponent for unloading stiffness deterioration
Exponent for basic strength deterioration

Rate of cyclic deterioration for negative loading

Rate of cyclic deterioration for positive loading

E $\quad$ Modulus of elasticity

F Concentrated force according to Figure 4

G Shear modulus

$h_{1} \quad$ The height of the beam connection plate 
$h_{3}$

$I_{2}$

$I_{3}$

$K_{1}$

$K_{2}$

$K_{3}$

$l_{2}$

$l_{3}$

$l_{1}$

$L A$

$L D$

$L K$

$L S$

$m$

$M_{1}$

$M_{2}$

$M_{3}$

$M_{c} M_{y}$

$N_{1}$

$N_{2}$

$N_{3}$

ResN

ResP

$t_{1}$

$t_{2}$

$t_{3}$

$t h \_P N$

$t h \_P p$

$t h \_P c N$
The height of each column connection plate

The moment inertia of the horizontal component in Figure 4

The moment inertia of the vertical component in Figure 4

The rigidity of each column connection plate

The total rigidity of the two column connection plates

The rigidity of the beam connection plate

The width of torsional plate

The width of the column connection plate

The width of the beam connection plate

Accelerated reloading stiffness deterioration

Post-capping strength deterioration

Unloading stiffness deterioration

Basic strength deterioration

Inner moment according to Figure 4

Moment in the strip of the beam connection plate

Moment in the strip of the torsional plate according to Figure 4

Moment in the strip of the column connection plate according to Figure 4

Ratio of capping moment to yield moment

Axial force in the strip of the beam connection plate

Axial force in the strip of the torsional plate according to Figure 4

Axial force in the strip of the column connection plate according to Figure 4

Residual strength ratio for negative loading

Residual strength ratio for positive loading

The thickness of the beam connection plate

The thickness of the torsional plate

The thickness of each column connection plate

Plastic rotation capacity for negative loading

Plastic rotation capacity for positive loading

Post-capping rotation capacity for negative loading
th_PcP Post-capping rotation capacity for positive loading

$t h \_u N \quad$ Ultimate rotation capacity for negative loading

$t h \_u P \quad$ Ultimate rotation capacity for positive loading

$V_{1} \quad$ Shear force in the strip of the beam connection plate

$V_{2} \quad$ Shear force in the strip of the torsional plate according to Figure 4

$V_{3} \quad$ Shear force in the strip of the column connection plate according to Figure 4

$a_{1} \quad$ Constant coefficient

$a_{2} \quad$ Constant coefficient

$a_{3} \quad$ Constant coefficient

$a_{n}, a_{i}, a_{4}, a_{5}, a_{6}$ Constant coefficients

$f_{s} \quad$ Shape factor

$\delta \quad$ The mid displacement of strips under the concentrated force in Figure 4

\section{References}

1. Moghaddam, H.A. and Estekanchi, H.E. "Seismic behavior of off-center bracing systems", J. of Constructional Steel Research, 51(2), pp. 177-196 (1999).

2. ASCE/SEI Seismic Rehabilitation Standards Committee, Seismic Rehabilitation of Existing Buildings (ASCE/SEI 41-06), American Society of Civil Engineers, Reston, VA (2007).

3. White, R.N. and Fang, P.J. "Framing connections for square structural tubing", J. of the Structural Division, 92(2), pp. 175-194 (1966).

4. Jones, M.H. "Tensile and shear behavior of fin-plate connections to hollow and concrete-filled steel tubular columns at ambient and elevated temperatures", $\mathrm{PhD}$ Thesis, The University of Manchester, UK (2008).

5. Wang, Y. "Robustness of connections to concrete-filled steel tubular columns under fire during heating and cooling", PhD Thesis, The University of Manchester, UK (2012).

6. Dawe, J. and Grondin, G. "W-shape beam to RHS column connections", Canadian J. of Civil Eng., 17(5), pp. 788-797 (1990).

7. Elghazouli, A.Y., Málaga-Chuquitaype, C., Castro, J.M., and Orton, A.H. "Experimental monotonic and cyclic behavior of blind-bolted angle connections", Engineering Structures, 31(11), pp. 2540-2553 (2009).

8. Málaga-Chuquitaype, C. and Elghazouli, A. "Behavior of combined channel/angle connections to tubular columns under monotonic and cyclic loading", Engineering Structures, 32(6), pp. 1600-1616 (2010).

9. Li, X. "Moment-rotation behavior of universal beam to tubular column connections using reverse channel", PhD Thesis, The University of Manchester, UK (2012). 
10. Maison, B.F., Rex, C.O., Lindsey, S.D., and Kasai, K. "Performance of PR moment frame buildings in UBC seismic zones 3 and 4", J. of Structural Eng., 126(1), pp. 108-116 (2000).

11. Abolmaali, A., Kukreti, A., Motahari, A., and Ghassemieh, M. "Energy dissipation characteristics of semirigid connections", J. of Constructional Steel Research, 65(5), pp. 1187-1197 (2009).

12. Braconi, A., Salvatore, W., Tremblay, R., and Bursi, O.S. "Behavior and modelling of partial-strength beam-to-column composite joints for seismic applications", Earthquake Eng. \& Struct. Dyn., 36(1), pp. 142-161 (2007).

13. Attarnejad, R. and Pirmoz, A. "Nonlinear analysis of damped semi-rigid frames considering momentshear interaction of connections", Int. J. of Mechanical Sciences, 81, pp. 165-173 (2014).

14. Brunesi, E., Nascimbene, R., and Rassati, G. "Seismic response of MRFs with partially-restrained bolted beam-to-column connections through FE analyses", J. of Constructional Steel Research, 107, pp. 37-49 (2015).

15. Moghadam, A. "Evaluation of semi rigid steel frame connection with torsional plate and its optimal placement", MSc Thesis, Sharif University of Technology, Tehran, Iran (2014).

16. Abaqus, H., Karlsson and Sorensen. Inc., Pawtucket, RI (1989).

17. ASTM, Specification for Structural Steel (A36-88c), American Society For Testing And Materials, Philadelphia (1988).

18. Standard 2800, Iranian Code of Practice for Seismic Resistant Design of Buildings, Third Revision, Building and Housing Research Center, Iran (in Persian) (2005).

19. ASCE 7-10, Minimum Design Loads for Building and Other Structures, American Society of Civil Engineers, ASCE, Virginia (2010).

20. AISC, Specification for Structural Steel Building, ANSI/AISC 360-10, American Institute of Steel Construction, Chicago (2010).

21. Chan, S.L. and Chui, P.T., Non-Linear Static and Cyclic Analysis of Steel Frames with Semi-Rigid Connections, Elsevier, Netherlands (2000).

22. Saritas, A. and Koseoglu, A. "Distributed inelasticity planar frame element with localized semi-rigid connections for nonlinear analysis of steel structures", Int. J. of Mechanical Sciences, 96, pp. 216-231 (2015).

23. Dogramaci Aksoylar, N., Elnashai, A.S., and Mahmoud, H. "Seismic performance of semi-rigid momentresisting frames under far and near field records", $J$. of Struct. Eng., 138(2), pp. 157-169 (2011).
24. Mazzoni, S., McKenna, F., Scott, M.H., and Fenves, G.L., OpenSees Command Language Manual, Pacific Earthquake Engineering Research (PEER) Center, Berkeley, CA (2006).

25. Wilson, E. and Habibullah, A., SAP2000, Integrated Finite Element Analysis and Design of Structures, Analysis Reference, Computers and Structures (1997).

26. Gupta, A. and Krawinkler, H. "Seismic demands for the performance evaluation of steel moment resisting frame structures", PhD Thesis, Stanford University, CA (1999).

27. Ibarra, L.F. and Krawinkler, H., Global Collapse of Frame Structures Under Seismic Excitations, Pacific Earthquake Engineering Research (PEER) Center, Berkeley, CA (2005).

28. Federal Emergency Management Agency, Quantification of Building Seismic Performance Factors, FEMA P695, Washington, D.C. (2009).

\section{Biographies}

Amin Moghadam received his MSc degree in Civil Engineering from Sharif University of Technology (SUT) in 2012. He was admitted as a PhD student at Kansas State University in 2016. He has worked as a Research Assistant in a broad range of structural and earthquake engineering areas with a special focus on the steel connections, control of structures, and retrofitting of the structures.

Homayoon Estekanchi is a Professor of Civil Engineering at Sharif University of Technology (SUT). $\mathrm{He}$ received his $\mathrm{PhD}$ degree in Civil Engineering from SUT in 1997 and has been a faculty member at SUT since then. $\mathrm{He}$ is a member of Iranian Construction Engineers Organization, ASCE, Iranian Inventors Association, and several other professional associations. His research interests include a broad area of topics in structural and earthquake engineering with a special focus on the development of the endurance time method and the value based seismic design.

Mohammad Yekrangnia is an Assistant Professor of Civil Engineering at Shahid Rajaee Teacher Training University. He received his $\mathrm{PhD}$ in Structural and Earthquake Engineering from Sharif University of Technology (SUT) where he also received his MSc degree. He received his BSc degree in Civil Engineering from Amirkabir University of Technology (Polytechnic of Tehran), Tehran, Iran. His research interests include seismic retrofit of masonry buildings, confined masonry, infilled frames, historic buildings, reinforced concrete buildings, and steel shear walls. 